\title{
Current status of insecticide resistance among malaria vectors in Kenya
}

Benyl M. Ondeto ${ }^{1,2^{*}}$, Christopher Nyundo ${ }^{1}$, Luna Kamau ${ }^{3}$, Simon M. Muriu ${ }^{4}$, Joseph M. Mwangangi ${ }^{1}$, Kiambo Njagi ${ }^{5}$, Evan M. Mathenge ${ }^{6}$, Horace Ochanda ${ }^{2}$ and Charles M. Mbogo ${ }^{1}$

\begin{abstract}
Background: Insecticide resistance has emerged as one of the major challenges facing National Malaria Control Programmes in Africa. A well-coordinated national database on insecticide resistance (IRBase) can facilitate the development of effective strategies for managing insecticide resistance and sustaining the effectiveness of chemical-based vector control measures. The aim of this study was to assemble a database on the current status of insecticide resistance among malaria vectors in Kenya.

Methods: Data was obtained from published literature through PubMed, HINARI and Google Scholar searches and unpublished literature from government reports, research institutions reports and malaria control programme reports. Each data source was assigned a unique identification code and entered into Microsoft Excel 2010 datasheets. Base maps on the distribution of insecticide resistance and resistance mechanisms among malaria vectors in Kenya were generated using ArcGIS Desktop 10.1 (ESRI, Redlands, CA, USA).

Results: Insecticide resistance status among the major malaria vectors in Kenya was reported in all the four classes of insecticides including pyrethroids, carbamates, organochlorines and organophosphates. Resistance to pyrethroids has been detected in Anopheles gambiae (s.s.), An. arabiensis and An. funestus (s.s.) while resistance to carbamates was limited to An. gambiae (s.s.) and An. arabiensis. Resistance to the organochlorine was reported in An. gambiae (s.s.) and An. funestus (s.s.) while resistance to organophosphates was reported in An. gambiae (s.l.) only. The mechanisms of insecticide resistance among malaria vectors reported include the $k d r$ mutations ( $\mathrm{L} 1014 \mathrm{~S}$ and L 1014F) and elevated activity in carboxylesterase, glutathione S-transferases (GST) and monooxygenases. The kdr mutations L $1014 \mathrm{~S}$ and L 1014F were detected in An. gambiae (s.s.) and An. arabiensis populations. Elevated activity of monooxygenases has been detected in both An. arabiensis and An. gambiae (s.s.) populations while the elevated activity of carboxylesterase and GST has been detected only in An. arabiensis populations.
\end{abstract}

Conclusions: The geographical maps show the distribution of insecticide resistance and resistance mechanisms among malaria vectors in Kenya. The database generated will provide a guide to intervention policies and programmes in the fight against malaria.

Keywords: Insecticide resistance, Mechanism of resistance, Anopheles, Malaria, Kenya

\footnotetext{
* Correspondence: muyomabo@gmail.com

${ }^{1}$ KEMRI, Centre for Geographic Medicine Research, Coast \& KEMRI Wellcome

Trust Research Programme, Kilifi, Kenya

${ }^{2}$ School of Biological Sciences, University of Nairobi, Nairobi, Kenya

Full list of author information is available at the end of the article
} 


\section{Background}

Malaria remains a major public health concern worldwide and has a profound socio-economic impact on countries where it is endemic [1]. Globally, in 2015 an estimated 429,000 deaths from malaria occurred most of which were in children aged under 5 years in Africa [2]. Africa bears the greatest burden of malaria accounting for approximately $92 \%$ of malaria deaths [2].

Vector control remains one of the central components for malaria control through larval source reduction and adult vector control. The two main methods of adult malaria vector control are indoor residual spraying (IRS) and the use of insecticide-treated nets (ITNs) [3]. Twelve insecticide products are currently available for malaria vector control, confined to four chemical classes: pyrethroids, organochlorines, organophosphates, and carbamates. At present, only pyrethroids are approved for use in ITNs, the single most important malaria control intervention, responsible for averting approximately $68 \%$ of malaria deaths in Africa [4]. However, the widespread use of chemical insecticides in vector control programmes and agriculture has led to the development of insecticide resistance in many parts of Africa [5-9], threatening to reverse current gains in malaria control $[10,11]$.

Toxicity of pyrethroids and organochlorine [Dichlorodiphenyltrichloroethane (DDT)] to insects has been attributed to their activity on the nervous system. The voltage-sensitive sodium channel is the major target site for pyrethroids and DDT. Acetylcholine is the transmitter at central nervous system synapses in insects. For the nervous system to operate properly, it is necessary that, once the appropriate message has been passed, excess acetylcholine should be removed from the synapse, to prevent repetitive firing and to allow a succeeding message to be transmitted [12]. This removal is effected by the enzyme acetylcholinesterase (AChE1), which catalyses the hydrolysis of the ester bond. Organophosphate and carbamate insecticides inhibit the esterase, and the result is that acetylcholine accumulates in the synapses, so that nerve function is impaired which ultimately leads to the death of the insect [12].

Resistance mechanisms underpinning phenotypic resistance observed in malaria vectors have been described in the past and categorised into the target site, metabolic, behavioural resistance and reduced penetration of the insecticides [13-16]. One mechanism of altered target site resistance is mediated through knock-down resistance $(k d r)$, involving point mutations in sodium channel genes in the mosquito's nervous system resulting in cross-resistance to pyrethroids and DDT $[17,18]$. The $k d r$ mutation may lead to a substitution of leucine at locus 1014 of the sodium channel gene in the wild-type for phenylalanine resulting in L 1014F, or the leucine may be substituted with serine resulting in L $1014 S$ [17, 18]. Another altered target site resistance involves mutations in the ace- $1^{R}$ gene resulting in insensitivity of acetylcholinesterase (AChE1) to carbamates and organophosphates. This mutation is caused by a single amino acid substitution, from a glycine to serine at the position 119, in the AChE1 catalytic site (G119S) $[15,16,19]$. In $\gamma$-aminobutyric acid (GABA)-mediated altered target site resistance, a single point mutation in the GABA receptor gene involving alanine-serine replacement in the heteromultimeric gated chloride ion channel results in resistance to dieldrin ( $R d l)$ [20].

Metabolic resistance mechanisms are mediated by overexpression of metabolic enzymes by mosquito vectors in response to xenobiotic compounds. In response to selection pressure by organophosphates and carbamates, non-specific esterases (NSE) are overexpressed while DDT and pyrethroids leads to overexpression of cytochrome P450-dependent monooxygenases [21]. Glutathione-S-transferases (GST) elevation is significant in detoxification of organophosphates, DDT and pyrethroids [19]. The insect may produce increased quantities of these enzymes, which metabolise the insecticide, sequestrate the molecules so they cannot function and detoxification of the insecticide [16]. The over-expression of these enzymes may be as a result of gene amplification of the genes encoding these enzymes or changes in either trans-acting regulatory elements or the promoter region $[19,22]$.

Behavioural resistance was described by WHO in 1957 as 'development of the ability to avoid a dose which would prove lethal' [14] and is attributed to the irritant property of some insecticides which causes the malaria vectors to avoid sprayed surfaces. Studies have shown a shift in vectors biting preferences from indoor to outdoor and a change in behaviour from late night-biting to early nightbiting to avoid insecticide-treated houses [23, 24].

Another important resistance mechanism is reduced penetration of insecticides which is mediated through cuticular thickening in insects leading to slower rates of insecticide absorption. This is an important mechanism when coupled with other mechanisms such as metabolic detoxification as it provides ample time for detoxifying enzymes to metabolise the chemical [13]. Studies have indicated that cuticular thickness is greater in pyrethroid resistant mosquitoes as compared to the pyrethroid susceptible mosquitoes [25].

In Kenya, the first reported case of resistance to pyrethroids in malaria vectors was in the context of insecticide-treated net use in western Kenya where reduced knockdown rates were observed [26]. Since then, widespread resistance to pyrethroid and DDT in malaria vectors have been reported in different parts 
of the country [9, 27-31]. Most studies in Kenya have focused on testing for $k d r$ mutation in malaria vectors [31-35] with only a few studies focusing on metabolic resistance [36, 37] mainly due to difficulty in conducting metabolic tests [38]. Despite these difficulties, metabolic resistance requires further attention since it is likely to have more impact on the effectiveness of the insecticides than target-site resistance [38]. In addition, studies on target-site mechanism ace- $1^{R}$ gene are yet to be reported. Therefore, more studies need to be conducted urgently to provide a status update on presence or absence of this resistance mechanism in the Anopheles vectors and to monitor the spread of this resistance gene. This is crucial because carbamate and organophosphate insecticides have been suggested as a potential alternative to manage pyrethroid-resistant populations [8].

Several efforts have been made previously in Africa to generate databases on malaria vectors resistant to insecticides at national or continental level [18, 39-42]. These databases are crucial components in the monitoring, detection and management of insecticide resistance in vector species. In Kenya, studies on insecticide resistance to malaria vectors have increased over the years. Therefore, there is need to build an insecticide resistance database (IRbase) that will collate this data and enable policy makers to make rational decisions on proper and timely entomological and resistance monitoring that is evidence-based. The IRBase will be a geospatial database that will generate information essential to aid decision support systems to inform effective insecticide policy making by the Kenya National Malaria Control Programme.

The main aim of this study was to assemble a comprehensive Kenyan IRBase on the current status of insecticide resistance among malaria vectors in Kenya. The IRBase will be a valuable resource for use by the Kenya National Malaria Control Programme and other stakeholders involved in the monitoring and management of insecticide resistance.

\section{Methods}

\section{Comprehensive literature search}

A comprehensive search of online bibliographic databases of published literature was conducted to extract and create a database on the status of insecticide resistance among malaria vectors in Kenya (Table 1). The databases used included PubMed (http://www.ncbi.nlm.nih.gov/ pubmed), HINARI (http://www.who.int/hinari/en/) and Google Scholar (http://scholar.google.com/). The key search terms formulated to guide scanning of published literature included Anopheles, insecticide bioassay, resistance, susceptible, susceptibility test, insecticide resistance mechanisms and Kenya. The unpublished literature was compiled from government reports, research institutions reports and malaria control programme reports (Table 1). The data extracted from unpublished sources had to adhere to standard WHO protocol thus a vigorous verification and authorization process was established [43]. The search period was confined to entomological surveys conducted between 1987 and 2015. This was deliberately done to ensure that the data collected included modern taxonomic species concepts such as cytological and molecular techniques which are capable of identifying sibling species within the An. gambiae and An. funestus complexes. The resulting literature was then reviewed retaining all references that met the following criteria for inclusion: (i) the reported study was undertaken after December 1986; (ii) the surveys reported primary data; (iii) the surveys provided study sites; (iv) the surveys reported the insecticide susceptibility tests or insecticides resistance mechanisms; and (v) the surveys adhered to the standard WHO protocol with the exception of permethrin in which different standard discriminating dosage $(0.25 \%)$ applied from 1981 until 1998 [44, 45].

\section{Data extraction and curation}

The data were extracted into Microsoft Excel 2010 datasheets. From each published article and report, the information extracted from each susceptibility or mechanisms test conducted included: mosquito collection period (year, start month, end month), location name (province first administrative level, district second administrative level, village or site), GPS coordinates (latitude UTM_X, longitude UTM_Y), vector mosquitoes species (species or species complexes tested, stage tested and origin), data source (institute that collected data, data published in a journal or not, journal reference) and remarks indicating deviations from standard procedures. For bioassays following the WHO susceptibility testing protocol, the information recorded included: test type (WHO test kit-Adult), insecticide tested (pyrethroids, carbamates, organochlorine and organophosphates), bioassays conducted (number of replicates tested, total mosquito in all test replicates, number of replicates for control, total mosquitoes in all controls), and phenotypic test outcomes (time at which mortality recorded, recorded average mortality in treatment (\%), recorded average mortality in controls (\%), calculated average mortality adjusted for control (\%), resistance status). The resistance status was based on recently revised WHO criteria: high, < 90\%; moderate, 90 97\%; and susceptible, $98-100 \%$ [43]. For biochemical or molecular mechanisms tests conducted, the following information was recorded: test type ( $k d r$ mutation- L $1014 S$ and L 1014F, elevated activity of carboxylesterase, glutathione S-transferases and monooxygenases) and mechanism outcomes (mechanism status, allelic frequency in \%). 


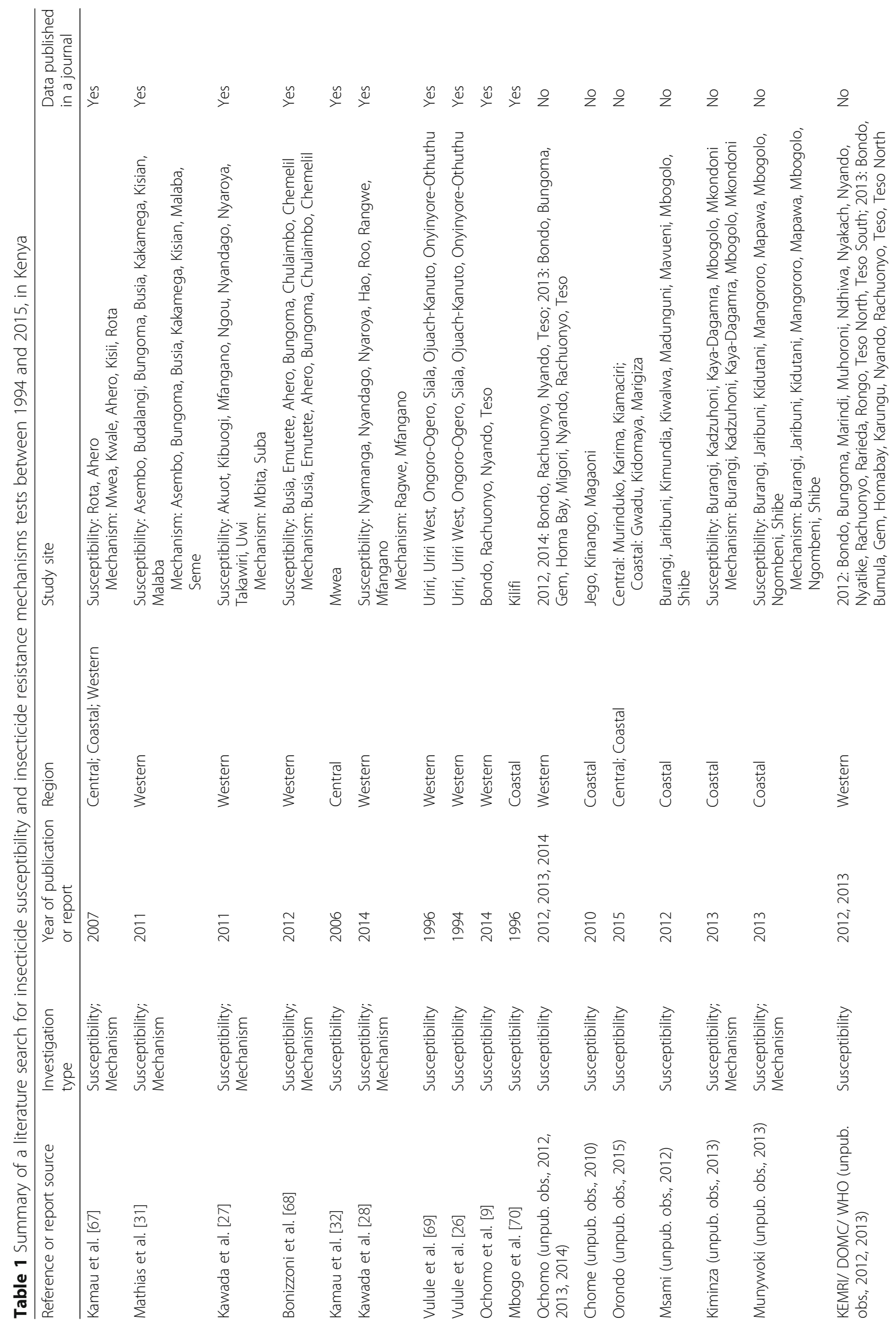




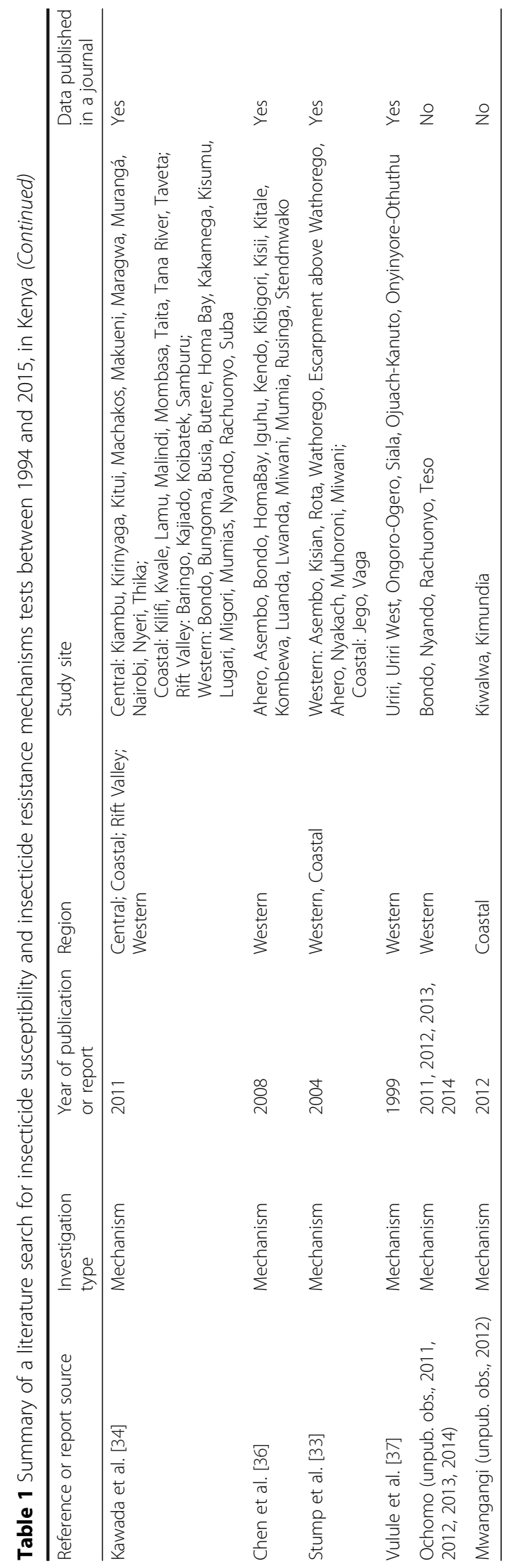




\section{Geo-referencing of study sites}

The study sites were geo-referenced using geographical coordinates provided in the research articles. Survey sites, whose geographical coordinates were not provided by the research articles, were geo-referenced using digital geographical databases, a collection of spatial data and related descriptive data organised for efficient storage and retrieval by many users, such as Microsoft Encarta, Google Earth (https://www.google.com/earth/) and Geonames (http://www.geonames.org/) [46].

\section{Generation of insecticide resistance maps and data summaries}

Data from survey sites entered into Microsoft Excel 2010 datasheets were imported and converted to database (dbase) files used to generate spatio-temporal distribution maps in ArcGIS Desktop 10.1 (ESRI, Redlands, CA, USA). Spatial distribution of insecticide resistance status (susceptible, moderate or high) and mechanism status (detected or not detected) for each of the malaria vectors across Kenya by province were displayed.

The data extracted were summarised using Microsoft Excel 2010 datasheets. The data obtained from provinces in Kenya was summarized into the following regions: Western region (Western and Nyanza provinces); Central region (Central and Nairobi provinces); Eastern region (Eastern Province), Northeastern region (North Eastern Province); Coastal region (Coast Province) and the Great Rift Valley region (Rift Valley Province).

\section{Results}

The search period between 1987 and 2015 yielded a total of 20 data articles (10 published and 10 unpublished) on insecticide susceptibility tests and 16 data articles (9 published and 7 unpublished) on insecticide resistance mechanisms that were identified and analysed (Table 2). The data articles that were obtained for this analysis were from 1994 to 2015 and none in the period between 1987 and 1993. The majority of data articles on insecticide susceptibility tests and insecticide resistance mechanisms occurred between 2009 and 2013.

Table 3 shows spatially unique survey sites reporting data for Anopheles species tested against the four classes of insecticides and the mechanisms of resistance in the regions of Kenya. Literature searches generated a total of 816 insecticide susceptibility data points and 473 insecticide resistance mechanisms data points of Anopheles species tested via recommended WHO methods [43]. Majority of the data points on insecticide susceptibility tests were from Western $(82.7 \%, n=675)$ and Coastal regions $(15.4 \%, n=126)$. Most studies $(76.6 \%, n=625)$ had tested resistance against pyrethroids mainly permethrin and deltamethrin. Few studies $(23.4 \%, n=191)$ focused on organophosphates (fenitrothion and malathion), carbamates (bendiocarb and propoxur) and organochlorines mainly DDT. However, a few studies conducted susceptibility tests in a study site more than once over the years for a given insecticide. Majority of the data points on resistance mechanisms were from Western $(70.2 \%, n=332)$ and Coastal regions (15.2\%, $n=72$ ). These studies had investigated mostly target-site resistance $(88.6 \%, n=419)(k d r$ mutations- L $1014 S$ and $\mathrm{L} 1014 \mathrm{~F}$ ) and very few studies on metabolic resistance $(11.4 \%, n=54)$ including elevated activity of monooxygenases, carboxylesterase and glutathione $\mathrm{S}$-transferases.

A summary of different classes of insecticides tested against malaria vectors in Kenya showed the differential level of response (Table 4). Pyrethroid and DDT resistance in the Anopheles species tested ranged from complete susceptibility to very high levels of resistance (Table 4). Anopheles arabiensis showed low frequency of pyrethroid resistance in Coastal and Central regions (Additional file 1: Figures S1- S3; Table 4) and also remained susceptible to DDT in the regions tested (Additional file 1: Figure S6; Table 4). The An. funestus species showed high resistance to pyrethroids in Western and Coastal regions whereas, in the Central region, it showed susceptibility (Additional file 1: Figures S1, S2; Table 4). Across all regions, the Anopheles species tested demonstrated high pyrethroid resistance, although some sites in Coastal and Central regions had low to moderate resistance (Fig. 1; Additional file 1: Figures S1-S5). These Anopheles species were largely susceptible to organochlorine (DDT) across most regions of Kenya with a few cases of high resistance reported in the western region (Fig. 1; Additional file 1: Figure S6).

Against organophosphates, the majority of the Anopheles species tested showed susceptibility to these insecticides (Table 4; Fig. 1). However, a few cases of moderate resistance to fenitrothion were reported in the Coastal region and high resistance in An. gambiae (s.l.) reported in one site in the Coastal region (Additional file 1: Figure S7). Susceptibility to malathion was only tested for mosquitoes in the Western region of Kenya, and all Anopheles species tested remained susceptible to malathion in the Western region where it was only tested (Additional file 1: Figure S8).

Carbamates susceptibility in the Anopheles species tested varied from susceptible to moderate resistance (Table 4). The majority of the Anopheles species showed susceptibility to carbamates in all the regions of Kenya tested (Fig. 1) although An. gambiae (s.s.) and An. arabiensis were resistant to bendiocarb at two sites in the Western region (Additional file 1: Figure S9). Moderate level of resistance against carbamates was also reported in the Anopheles species tested in Western and Coastal regions (Additional file 1: Figures S9, S10). 
Table 2 Some publications and reports from which data were extracted on insecticide susceptibility and resistance mechanisms between 1994 and 2015, in Kenya

\begin{tabular}{|c|c|c|c|c|c|c|}
\hline & 1994-1998 & 1999-2003 & $2004-2008$ & 2009-2013 & 2014-2015 & Total \\
\hline \multicolumn{7}{|c|}{ Insecticide susceptibility data } \\
\hline Published data & 3 & 0 & 2 & 3 & 2 & 10 \\
\hline Unpublished data & 0 & 0 & 0 & 8 & 2 & 10 \\
\hline Total & 3 & 0 & 2 & 11 & 4 & 20 \\
\hline \multicolumn{7}{|c|}{ Insecticide resistance mechanism data } \\
\hline Published data & 0 & 1 & 3 & 4 & 1 & 9 \\
\hline Unpublished data & 0 & 0 & 0 & 6 & 1 & 7 \\
\hline Total & 0 & 1 & 3 & 10 & 2 & 16 \\
\hline
\end{tabular}

The $k d r$ mutation L 1014S in Anopheles species tested was widespread in the Western region and spreading to the Great Rift Valley, Central, Eastern and Coastal regions (Fig. 2; Additional file 2: Figure S1). The $k d r$ mutation L $1014 \mathrm{~F}$ in Anopheles species tested has only been detected in the Western region (Fig. 2; Additional file 2: Figure S2). Similar tests in other regions did not reveal the presence of this mutation. Elevated activity of monooxygenases in Anopheles species tested is widespread in the Western region and spreading to the Great Rift Valley, Central, Eastern and Coastal regions (Fig. 2; Additional file 2: Figure S3) whereas elevated activity of carboxylesterase and glutathione S-transferases in Anopheles species tested has only been detected in the Western region (Fig. 2; Additional file 2: Figures S4, S5).

\section{Discussion}

The current study has elucidated information on continued occurrence of insecticide resistance in different parts of Kenya that threatens the sustainability of vector control programmes. Consequently, this calls for an urgent need to incorporate annual monitoring of insecticide resistance across the malaria endemic zones in the Kenya Malaria Indicator Survey [47] as per the Global Plan for Insecticide Resistance Management [38]. Although the levels of insecticide resistance may vary across landscapes, even within small geographical scales and at different seasons, the drivers of such variations to insecticide resistance in Anopheles population has been attributed to several factors. For example, previous studies [48-50] have linked resistance to selection pressure driven by contamination of malaria vector breeding sites through the application of agricultural pesticides. Kenya, a largely agricultural country is not immune to use of agricultural pesticides that may impact on the performance of insecticides against malaria vectors. For example, carbofuran (carbamate) is used as a pesticide in irrigated rice areas [51] that also provide ideal habitats for mosquito breeding. Furthermore, intensification of insecticide use in public health has also exacerbated the mosquito resistance to pyrethroids. For example, according to surveys conducted by the Kenya Malaria Indicator

Table 3 Spatially unique survey sites by region that report data for Anopheles species that were tested against the four classes of insecticides using WHO insecticide susceptibility tests and insecticide resistance mechanisms tested using standard biochemical or molecular methods between 1994 and 2015, in Kenya

\begin{tabular}{|c|c|c|c|c|c|}
\hline & Central & Coastal & Western & Eastern & The Great Rift Valley \\
\hline \multicolumn{6}{|l|}{ Insecticide class } \\
\hline Pyrethroids & 9 & 64 & 552 & - & - \\
\hline Organophosphates & 1 & 21 & 47 & - & - \\
\hline Carbamates & 1 & 20 & 47 & - & - \\
\hline Organochlorines & 4 & 21 & 29 & - & - \\
\hline \multicolumn{6}{|l|}{ Mechanism type } \\
\hline kdr L1014S & 14 & 46 & 256 & 8 & 13 \\
\hline kdr L1014F & 9 & 20 & 40 & 6 & 7 \\
\hline Monooxygenases & 4 & 6 & 28 & 2 & 6 \\
\hline Carboxylesterase & $--^{a}$ & - & 4 & - & - \\
\hline Glutathione S-transferases & - & - & 4 & - & - \\
\hline
\end{tabular}

a"-", test not done 


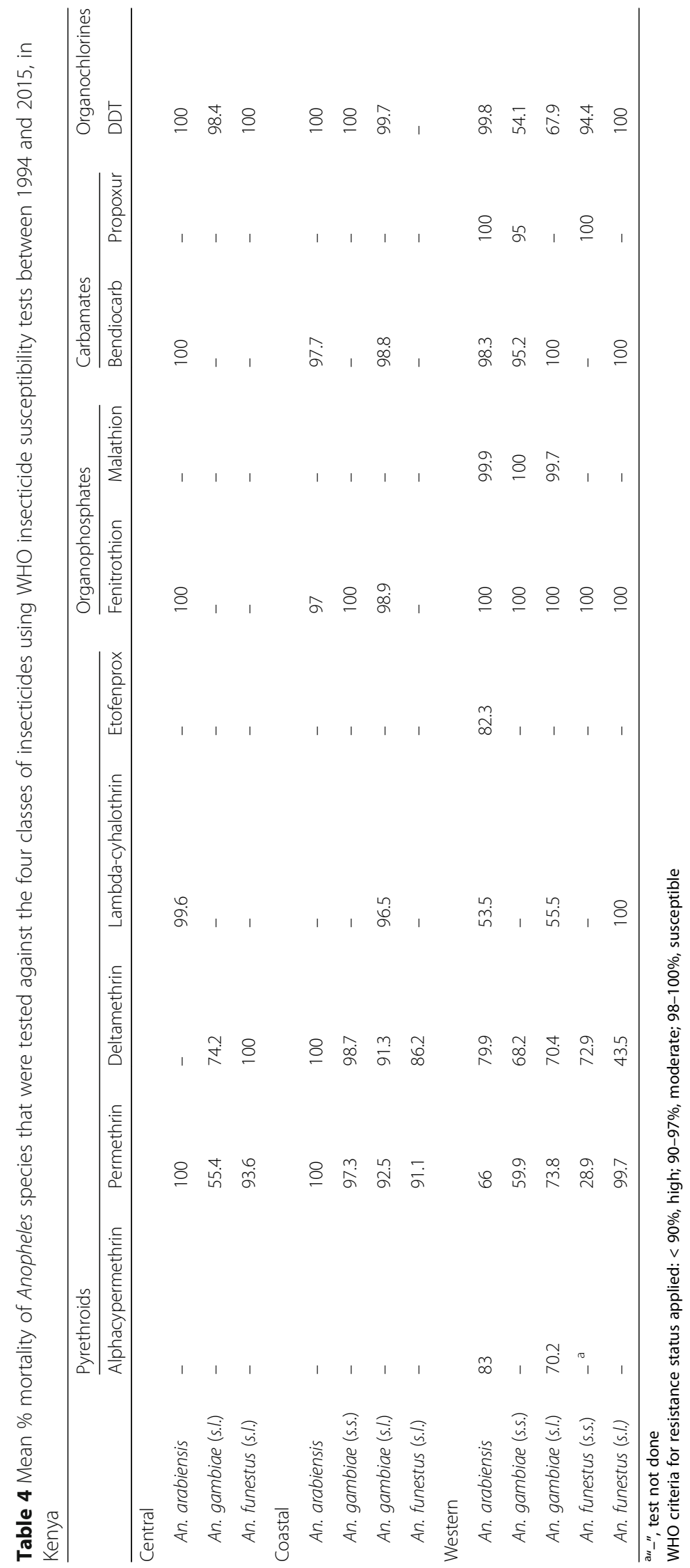




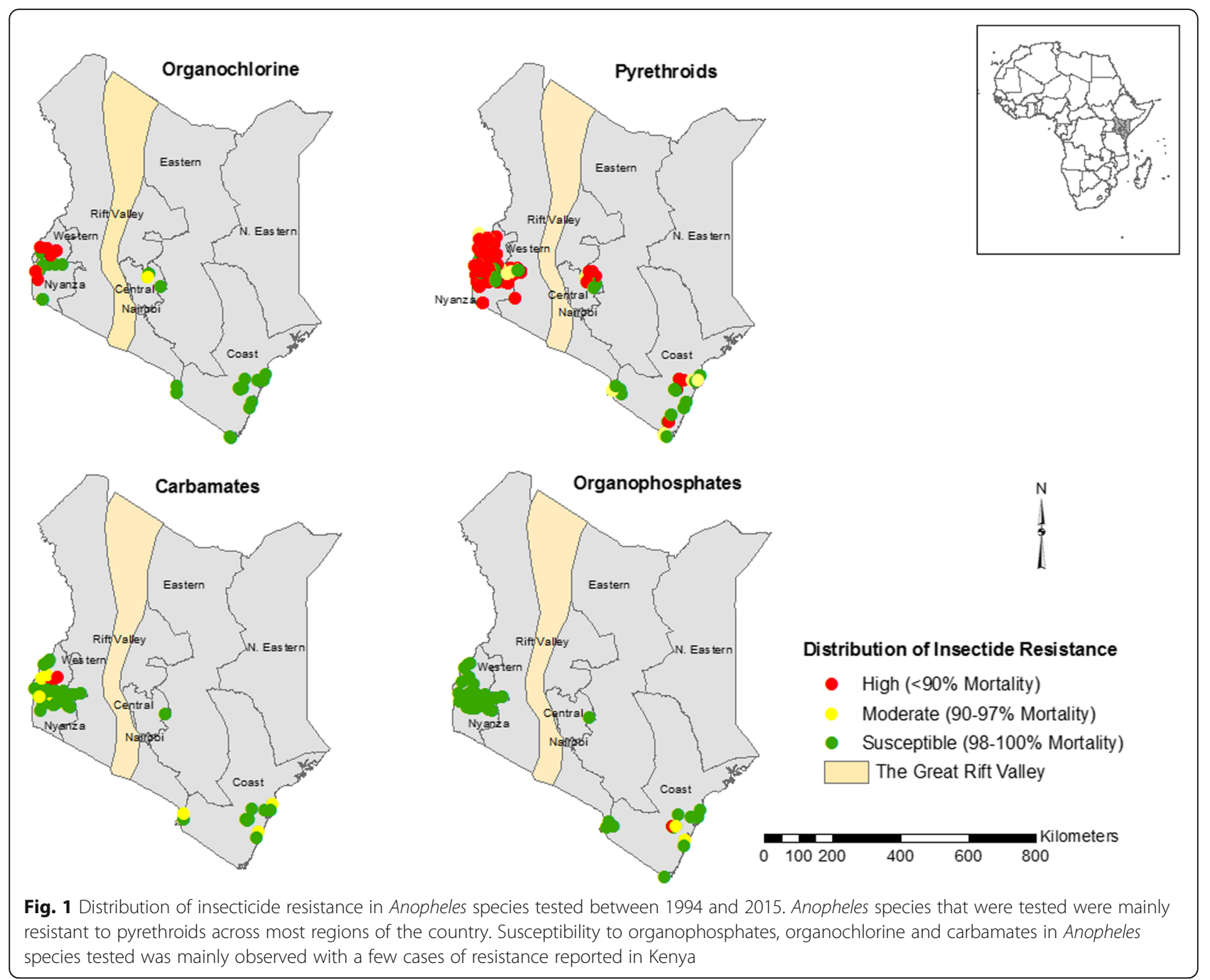

Survey, LLINs use among the household population has increased from $44 \%$ in the 2010 survey to $63 \%$ in the 2015 survey [47]. In malaria endemic regions of Kenya such as Western and Coastal regions, the scale-up of ITNs use, and implementation of IRS programs that rely heavily on pyrethroid insecticides may contribute to selection pressure exerted on malaria vectors against pyrethroid-based insecticides [26, 31]. Selection of low susceptible Anopheles populations in Kenya could also be driven by migration of resistant malaria vector population from neighbouring regions like Uganda where high resistance to pyrethroids have been reported $[9,31$, 52]. Moreover, all these factors may act synergistically rather than in isolation to drive insecticide resistance in the region and may threaten the impact of vector control programmes using these insecticides.

Insecticide resistance to organochlorines, organophosphates and carbamates in Kenya is not widespread largely because their use is limited in Kenya especially in public health. The use of particular organochlorine like
DDT is prohibited in any form in the country, and its resistance is only attributed to cross-resistance from pyrethroids and possible population overflow from Uganda into the neighbouring Western region in Kenya [9]. Organophosphates use is limited to agricultural settings against insect pests. Fenitrothion (organophosphate) and carbofuran (carbamate) are used in agricultural systems [51] and could contribute to resistance reported in areas where they are used in agricultural settings [53]. Organophosphates and carbamates have been considered for IRS as an alternative vector control tool against pyrethroids-resistant malaria vectors [8] however sporadic resistance to these insecticides have been reported in Kenya thus justifies the urgent need of an annual resistance monitoring if they are to be considered for IRS in targeted endemic areas.

According to studies reviewed, $k d r$ mutation L $1014 S$ was widely reported in An. arabiensis and An. gambiae (s.s.) in the regions tested in Kenya. This is consistent with earlier studies conducted by Santolamazza et al. [18] that 


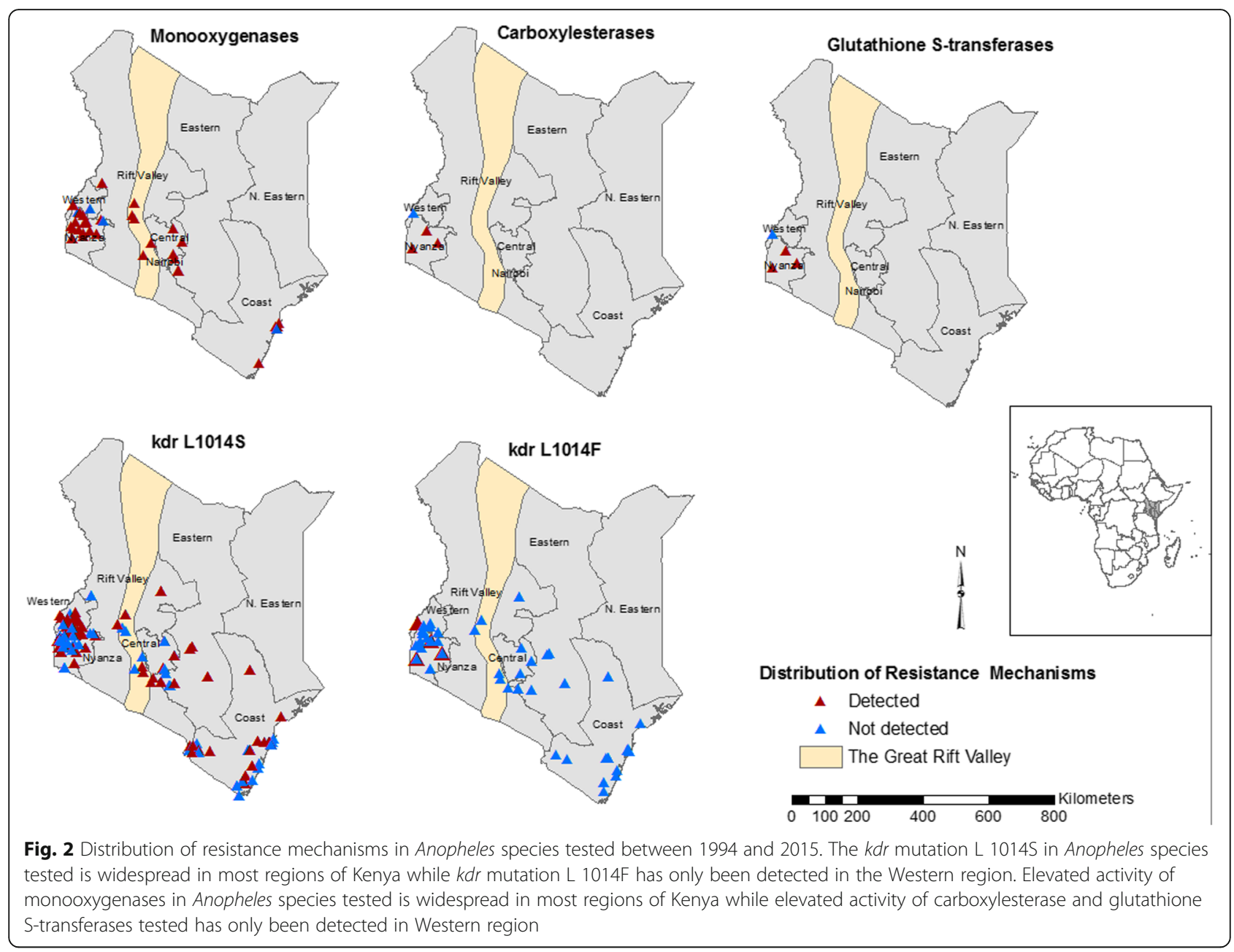

analysed the distribution of $k d r$ mutation L $1014 S$ in $A n$. gambiae populations and found this mutation to be predominantly found in East African countries [34, 50, 54]. However, knockdown resistance mutation L 1014F was first reported by Ochomo et al. [35] in studies conducted in western Kenya. This mechanism is widespread in West Africa $[7,18,55]$ but has recently been reported in eastern African countries; Uganda [56], Ethiopia [57], Sudan [58], Tanzania [59] and more recently in Kenya [35].

The majority of the investigations on the insecticide resistance mechanism were on target site mutations $(k d r)$ with a few being on metabolic resistance. The WHO [38] attributes this tendency to the fact that metabolic resistance assays require more stringent testing conditions as fresh mosquitoes are required which are difficult to transport and also are relatively difficult to conduct due to high costs in addition to the interpretation of results that requires strong technical skills. Mosquitoes that have been dead for more than a few minutes at room temperature will have the enzyme levels extremely reduced and degraded hence quantification of enzyme levels may produce inaccurate results $[38,60]$. Despite these challenges, more focus should be put on metabolic resistance as evidence has shown that metabolic mechanisms play a bigger role in insecticide resistance than target-site resistance [38].

A large proportion of insecticide resistance mechanism studies, as well as the insecticide susceptibility tests, was mostly focussed on An. gambiae populations compared to the An. funestus populations. This propensity to test An. gambiae as opposed to An. funestus could be attributed to the difficulty in rearing the progeny of field-collected mosquitoes of this species to obtain large numbers needed to carry out WHO susceptibility tests, biochemical, genetic and molecular tests [61, 62]. Regardless of this difficulty, more information on the insecticide susceptibility and mechanism of An. funestus population is important to monitor, detect and manage insecticide resistance among this vector species as high level of insecticide resistance has already been reported in South Africa [63]. Anopheles funestus is an important vector of malaria in Kenya as it plays an important role in malaria transmission [64-66] and thus warrants insecticide resistance monitoring. 
In Africa, there has been an effort to create databases and map the insecticide resistance among the malaria vectors at national or continental scale [18, 39-42]. These databases are necessary to monitor, detect and manage insecticide resistance. In Kenya, the IRbase has been consolidated to collate all historical data and current data on insecticide resistance status among malaria vectors in the country. The limitations that were faced while consolidating this database are similar to previous databases that have been generated before $[18,39-42]$. In most cases, the studies did not provide geo-coordinates for the study sites thus these sites were geo-referenced using digital geographical databases. A problem encountered with geo-coordinates provided in digital geographical databases is that they are not specifically accurate to the sites where mosquito collections were conducted. From the geospatial maps developed, insecticide resistance data is largely limited to areas with intense malaria vector research that has been conducted over time, and this could be attributed to the proximity to the research institutions. In addition, there have been very few studies in areas where malaria transmission intensity is low. Blank parts in the maps indicated unavailability of published or unpublished sources on insecticide susceptibility and resistance mechanisms from such areas. It is obvious from the maps presented that large areas of the country had no information on insecticide susceptibility and resistance mechanisms among malaria vectors. Thus, there is an urgent need for baseline surveys to be carried out in malaria regions to develop a comprehensive and reliable database for effective insecticide resistance monitoring and management. The IRbase generated is easy to use and interpret and will also be easily accessible by the Kenya National Malaria Control Programme and other stakeholders involved in the monitoring and management of insecticide resistance.

Assembling a spatio-temporal defined database of insecticide resistance distribution and insecticide resistance mechanism among malaria vectors in Kenya provides a platform for the future compilation of data. The database was tailored to promote the design of a systematic national monitoring of insecticide resistance while providing a platform for future data sharing. This IRbase developed for Kenya will provide an easy guide and accessible information for malaria control managers. The maps generated provide crucial information on the geographical extent of the status of insecticide resistance and insecticide resistance mechanisms for each region in the country. This provides useful information for guiding targeted resource allocation depending on the information needed for each malaria prone area and helps inform decisions to increase insecticide resistance surveillance in areas with little or no information. The IRbase may form the basis for determining if there are temporal changes in the insecticide susceptibility and resistance mechanism following vector control interventions. By providing information on the dynamic nature of insecticide resistance, the IRbase allows for the planning of appropriate vector interventions strategies where evidence-based decision-making on the appropriate classes of insecticide to be used will be possible. Up to date data from published journal articles and unpublished data will be included in the database yearly for effective monitoring of insecticide resistance and development of appropriate control tools. The IRbase generated will be stored at KEMRI-Wellcome Trust Research Programme database and can be accessed by writing to Prof. Charles Mbogo (Cmbogo@kemriwellcome.org).

\section{Conclusions}

From the available literature examined in this study, phenotypic resistance is observed throughout Kenya with increasing resistance in the Western region of the country. Two mechanisms of resistance, metabolic and $k d r$ mutation were identified. Thus, a well-coordinated malaria insecticide resistance database (IRBase) in Kenya will help the Kenya National Malaria Control Programme monitor and manage insecticide resistance and assist in the development of improved vector control strategies. Kenya has data on the insecticide resistance currently available, but it is largely limited to areas with intense malaria vector research that has been conducted over time and thus the need to conduct a country-wide analysis in malaria zones to establish the resistance situation. Monitoring and detection of insecticide resistance should be an essential component of all national malaria control efforts to ensure that the most effective vector control methods are being used.

\section{Additional files}

Additional file 1: Figure S1. Malaria vectors susceptibility status against permethrin. Figure S2. Malaria vectors susceptibility status against deltamethrin. Figure S3. Malaria vectors susceptibility status against lambda-cyhalothrin. Figure S4. Malaria vectors susceptibility status against alpha-cypermethrin. Figure S5. Malaria vectors susceptibility status against etofenprox. Figure S6. Malaria vectors susceptibility status against DDT. Figure S7. Malaria vectors susceptibility status against fenitrothion. Figure S8. Malaria vectors susceptibility status against malathion. Figure S9. Malaria vectors susceptibility status against bendiocarb. Figure S10. Malaria vectors susceptibility status against propoxur. (TIFF $9751 \mathrm{~kb}$ )

Additional file 2: Figure S1. Status of $k d r$ L1014S insecticide resistance mechanism among malaria vectors. Figure S2. Status of $k d r$ L1014F insecticide resistance mechanism among malaria vectors. Figure S3. Status of monooxygenases insecticide resistance mechanism among malaria vectors. Figure S4. Status of carboxylesterase insecticide resistance mechanism among malaria vectors. Figure S5. Status of glutathione S-transferase insecticide resistance mechanism among malaria vectors. (TIFF $4573 \mathrm{~kb}$ ) 


\section{Abbreviations}

AchE1: Acetylcholinesterase; DDT: Dichlorodiphenyltrichloroethane; DOMC: Division of Malaria Control; GABA: $\gamma$-aminobutyric acid; GPS: Global positioning system; GST: Glutathione S-transferases; IRBase: Insecticide resistance database; IRS: Insecticide residual spraying; ITNs: Insecticide-treated nets; kdr: Knockdown resistance; KEMRI: Kenya Medical Research Institute; NSE: Non-specific esterases; Rdl: Dieldrin; WHO: World Health Organization

\section{Acknowledgments}

We thank Ephantus J. Muturi and Elijah O. Juma for their comments on the draft. The authors are grateful to the Director, KEMRI for the permission to publish this data.

\section{Funding}

This research was funded by the Bill and Melinda Gates Foundation through the World Health Organization (Award \#45785 to Prof. Charles Mbogo).

\section{Availability of data and materials}

The data supporting the conclusions of this article are included within the article. Raw data and materials are available from the corresponding author upon request.

\section{Authors' contributions}

BMO, LK, KN, EMM and CMM conceived, designed and developed the study. BMO, SMM, JMM, HO and CMM contributed to the development of the methodology and data analysis. BMO collated data, and BMO and CN conducted data verifications for the database. BMO wrote the first draft of the manuscript and $\mathrm{CN}$ generated the maps. All authors read and approved the final manuscript.

\section{Ethics approval and consent to participate}

Not applicable.

\section{Consent for publication}

Not applicable.

\section{Competing interests}

The authors declare they have no competing interests.

\section{Publisher's Note}

Springer Nature remains neutral with regard to jurisdictional claims in published maps and institutional affiliations.

\section{Author details}

'KEMRI, Centre for Geographic Medicine Research, Coast \& KEMRI Wellcome Trust Research Programme, Kilifi, Kenya. ${ }^{2}$ School of Biological Sciences, University of Nairobi, Nairobi, Kenya. ${ }^{3}$ KEMRI, Centre for Biotechnology Research and Development, Nairobi, Kenya. ${ }^{4}$ Department of Biological Sciences, Pwani University, Kilifi, Kenya. ${ }^{5}$ Ministry of Health, Malaria Control Unit, Nairobi, Kenya. ${ }^{6} \mathrm{KEMRI}$, Eastern and Southern Africa Centre of International Parasite Control, Nairobi, Kenya.

\section{Received: 18 February 2017 Accepted: 4 September 2017}

\section{Published online: 19 September 2017}

\section{References}

1. Gallup JL, Sachs JD. The economic burden of malaria. Am J Trop Med Hyg. 2001;64(1-2 Suppl):85-96.

2. WHO. World Malaria Report 2016. Geneva: World Health Organization; 2016. http://www.who.int/malaria/publications/world-malaria-report-2016/report/en/.

3. Greenwood B. Can malaria be eliminated ? Trans R Soc Trop Med Hyg. 2009;103(Suppl 1):S2-5.

4. Bhatt S, Weiss DJ, Cameron E, Bisanzio D, Mappin B, Dalrymple U, et al. The effect of malaria control on Plasmodium falciparum in Africa between 2000 and 2015. Nature. 2015;526(7572):207-11.

5. Kamgang B, Marcombe S, Chandre F, Nchoutpouen E, Nwane P, Etang J, et al. Insecticide susceptibility of Aedes aegypti and Aedes albopictus in Central Africa. Parasit Vectors. 2011;4:79.

6. Protopopoff N, Matowo J, Malima R, Kavishe R, Kaaya R, Wright A, et al. High level of resistance in the mosquito Anopheles gambiae to pyrethroid insecticides and reduced susceptibility to bendiocarb in north-western Tanzania. Malar J. 2013:12:149.

7. Koffi AA, Alou LPA, Kabran JK, N'Guessan R, Pennetier C. Re-visiting insecticide resistance status in Anopheles gambiae from cote d'Ivoire : a nation-wide informative survey. PLoS One. 2013;8:12.

8. Aïzoun N, Aïkpon R, Gnanguenon V, Oussou O, Agossa F, Padonou GG, et al. Status of organophosphate and carbamate resistance in Anopheles gambiae sensu lato from the south and north Benin, West Africa. Parasit Vectors. 2013;6:274

9. Ochomo E, Bayoh NM, Kamau L, Atieli F, Vulule J, Ouma C, et al. Pyrethroid susceptibility of malaria vectors in four districts of western Kenya. Parasit Vectors. 2014;7:310.

10. Hemingway J, Ranson H, Magill A, Kolaczinski J, Fornadel C, Gimnig J, et al. Averting a malaria disaster: will insecticide resistance derail malaria control? Lancet. 2016;387:1785-8.

11. WHO. World Malaria Report 2015. Geneva: World Health Organization; 2015. http://www.who.int/malaria/publications/world-malaria-report-2015/report/en/.

12. Rita Z, Kumar Senthil NGG. Insecticides - their mode of action in mosquito and possibility of resistance. Sci Vis. 2009;9(2):85-91.

13. Plapp FW. Biochemical genetics of insecticide resistance. Annu Rev Entomol. 1976;21:179-97.

14. WHO. Expert committee on insecticides: seventh report. Geneva: World Health Organization; 1957. http://www.who.int/iris/handle/10665/40380.

15. Hemingway J, Karunaratne SHPP. Mosquito carboxylesterases: a review of the molecular biology and biochemistry of a major insecticide resistance mechanism. Med Vet Entomol. 1998;12(1):1-12.

16. Hemingway J. The molecular basis of two contrasting metabolic mechanisms of insecticide resistance. Insect Biochem Mol Biol. 2000;30(11):1009-15.

17. Silva APB, Santos JMM, Martins AJ. Mutations in the voltage-gated sodium channel gene of anophelines and their association with resistance to pyrethroids - a review. Parasit Vectors. 2014;7:450.

18. Santolamazza F, Calzetta M, Etang J, Barrese E, Dia I, Caccone A, et al. Distribution of knock-down resistance mutations in Anopheles gambiae molecular forms in west and west-central Africa. Malar J. 2008;7:74.

19. Hemingway J, Ranson $\mathrm{H}$. Insecticide resistance in insect vectors of human disease. Annu Rev Entomol. 2000;45:371-91.

20. Wondji CS, Dabire RK, Tukur Z, Irving H, Djouaka R, Morgan JC. Identification and distribution of a GABA receptor mutation conferring dieldrin resistance in the malaria vector Anopheles funestus in Africa. Insect Biochem Mol Biol. 2011;41(7):484-91.

21. Fonseca-gonzález I, Quiñones ML, Mcallister J, Brogdon WG. Mixed-function oxidases and esterases associated with cross-resistance between DDT and lambda-cyhalothrin in Anopheles darlingi root 1926 populations from Colombia. Mem Inst Oswaldo Cruz. 2009;104(1):18-26.

22. Hemingway J, Hawkes N, Prapanthadara L, Jayawardenal KGl, Ranson H. The role of gene splicing, gene amplification and regulation in mosquito insecticide resistance. Philos Trans R Soc Lond B Biol Sci. 1998;353(1376):1695-9.

23. Ojuka P, li YB, Denoeud-ndam L, Nabasumba C, Muller Y, Okia M, et al. Early biting and insecticide resistance in the malaria vector Anopheles might compromise the effectiveness of vector control intervention in southwestern Uganda. Malar J. 2015;14:148.

24. Moiroux N, Gomez MB, Pennetier C, Elanga E, Djènontin A, Chandre F, et al. Changes in Anopheles funestus biting behavior following universal coverage of long-lasting insecticidal nets in Benin. J Infect Dis. 2012;206(10):1622-9.

25. Awolola TS, Oduola OA, Strode C, Koekemoer LL, Brooke B, Ranson H. Evidence of multiple pyrethroid resistance mechanisms in the malaria vector Anopheles gambiae sensu stricto from Nigeria. Trans R Soc Trop Med Hyg. 2009;103(11):1139-45.

26. Vulule J, Beach R, Atieli F, Roberts J, Mount D, Mwangi R. Reduced susceptibility of Anopheles gambiae to permethrin associated with the use of permethrin-impregnated bednets and curtains in Kenya. Med Vet Entomol. 1994:8:71-5.

27. Kawada H, Dida GO, Ohashi K, Komagata O, Kasai S, Sonye G, et al. Multimodal pyrethroid resistance in malaria vectors, Anopheles gambiae s.S., Anopheles arabiensis, and Anopheles funestus s.s. in western Kenya. PLoS One. 2011;6:8

28. Kawada H, Ohashi K, Dida GO, Sonye G, Njenga SM, Mwandawiro C, et al. Insecticidal and repellent activities of pyrethroids to the three major pyrethroid-resistant malaria vectors in western Kenya. Parasit Vectors. $2014 ; 7: 208$. 
29. Mulamba C, Riveron JM, Ibrahim SS, Irving H, Barnes KG, Mukwaya LG, et al. Widespread pyrethroid and DDT resistance in the major malaria vector Anopheles funestus in East Africa is driven by metabolic resistance mechanisms. PLoS One. 2014:9:10.

30. Wanjala CL, Mbugi JP, Ototo E, Gesuge M, Afrane YA, Atieli HE, et al. Pyrethroid and DDT resistance and organophosphate susceptibility among Anopheles spp. mosquitoes, western Kenya. Emerg Infect Dis. 2015;21(12):2178-81.

31. Mathias DK, Ochomo E, Atieli F, Ombok M, Bayoh MN, Olang G, et al. Spatial and temporal variation in the kdr allele L1014S in Anopheles gambiae s.S. and phenotypic variability in susceptibility to insecticides in western Kenya. Malar J. 2011;10:10.

32. Kamau L, Vulule JM. Status of insecticide susceptibility in Anopheles arabiensis from Mwea rice irrigation scheme, central Kenya. Malar J. 2006;5:46

33. Stump AD, Atieli FK, Vulule JM, Besansky NJ. Dynamics of the pyrethroid knockdown resistance allele in western Kenyan populations of Anopheles gambiae in response to insecticide-treated bed net trials. Am J Trop Med Hyg. 2004;70(6):591-6.

34. Kawada H, Futami K, Komagata O, Kasai S, Tomita T, Sonye G, et al. Distribution of a knockdown resistance mutation ( L1014S) in Anopheles gambiae s.s. and Anopheles arabiensis in western and southern Kenya. PLoS One. 2011;6:9

35. Ochomo E, Subramaniam K, Kemei B, Rippon E, Bayoh NM, Kamau L, et al. Presence of the knockdown resistance mutation, Vgsc-1014F in Anopheles gambiae and An. arabiensis in western Kenya. Parasit Vectors. 2015;8:616.

36. Chen H, Githeko AK, Githure Jl, Mutunga J, Zhou G, Yan G. Monooxygenaselevels and knockdown resistance $(k d r)$ allele frequencies in Anopheles gambiae and Anopheles arabiensis in Kenya. J Med Entomol. 2008;45(2):242-50.

37. Vulule JM, Beach RF, Atieli FK, Mcallister J, Brogdon W, Roberts J, et al. Elevated oxidase and esterase levels associated with permethrin tolerance in Anopheles gambiae from Kenyan villages using permethrin-impregnated nets. Med Vet Entomol. 1999;13:239-44.

38. WHO. Global plan for insecticide resistance management in malaria vectors. 2012.

39. ANVR. Atlas of insecticide resistance in malaria vectors of the WHO African region. 2005.

40. Coleman M, Sharp B, Seocharan I, Hemingway J. Developing an evidence-based decision support system for rational insecticide choice in the control of African malaria vectors. J Med Entomol. 2006;43(4): 663-8.

41. Ranson H, N'Guessan R, Lines J, Moiroux N, Nkuni Z, Corbel V. Pyrethroid resistance in African anopheline mosquitoes: what are the implications for malaria control? Trends Parasitol. 2011;27(2):91-8.

42. Knox TB, Juma EO, Ochomo EO, Jamet HP, Ndungo L, Chege P, et al. An online tool for mapping insecticide resistance in major Anopheles vectors of human malaria parasites and review of resistance status for the Afrotropical region. Parasit Vectors. 2014;7:7.

43. WHO. Test procedures for insecticide resistance monitoring in malaria vector mosquitoes. 2013

44. WHO. Test procedures for insecticide resistance monitoring in malaria vectors, bio-efficacy and persistence of insecticides on treated surfaces, report of WHO informal consultations. Geneva: WHO; 1998.

45. WHO. Instructions for determining the susceptibility or resistance of adult mosquitos to organochlorine, organophosphate and carbamate insecticides - diagnostic test. Geneva: WHO; 1981.

46. Natural Resourses Conservation Service USD of A. Cartographic and GIS technical note MT-1 (rev. 1); 2006. p. 1-36. http://www.nrcs.usda.gov/ Internet/FSE_DOCUMENTS/nrcs144p2_051844.pdf.

47. National Malaria Control Programme (NMCP), Kenya National Bureau of Statistics (KNBS), ICF International. Kenya Malaria Indicator Survey 2015. Nairobi and Maryland: Ministry of Health, Kenya; 2016.

48. Diabate A, Baldet T, Chandre F, Akogbeto M, Guiguemde RT, Darriet F, et al. The role of agricultural use of insecticides in resistance to pyrethroids in Anopheles gambiae s.l. in Burkina Faso. Am J Trop Med Hyg. 2002; 67(6):617-22.

49. Chouaibou M, Etang J, Brevault T, Nwane P, Hinzoumbe CK, Mimpfoundi R, et al. Dynamics of insecticide resistance in the malaria vector Anopheles gambiae s.l. from an area of extensive cotton cultivation in northern Cameroon. Trop Med Int Health. 2008;13(4):476-86.
50. Verhaeghen K, Bortel W, Van RP, Okello PE, Talisuna A, Coosemans M. Spatio-temporal patterns in $k d r$ frequency in permethrin and DDT resistant Anopheles gambiae s.s. from Uganda. Am J Trop Med Hyg. 2010;82(4):566-73.

51. Wandiga S, Lalah J, Kaigwara P, Taylor D, Klaine S, Carvalho F, et al. Pesticides in Kenya. In: Pesticide residues in coastal tropical ecosystems: distribution, fate and effects. London: Taylor and Francis Group; 2003. p. 49-80.

52. Ramphul U, Boase T, Bass C, Okedi LM, Donnelly MJ, Müller P. Insecticide resistance and its association with target-site mutations in natural populations of Anopheles gambiae from eastern Uganda. Trans R Soc Trop Med Hyg. 2009;103:1121-6.

53. Ngala CJ, Kamau L, Mireji PO, Mburu J, Mbogo C. Insecticide resistance, host preference and Plasmodium falciparum parasite rates in Anopheles mosquitoes in Mwea and Ahero rice schemes. J Mosq Res. 2015;5(14):1-8.

54. Matowo J, Kitau J, Kaaya R, Kavishe R, Wright A, Kisinza W, et al. Trends in the selection of insecticide resistance in Anopheles gambiae s.l. mosquitoes in northwest Tanzania during a community randomized trial of longlasting insecticidal nets and indoor residual spraying. Med Vet Entomol. 2015;29:51-9.

55. Ibrahim SS, Manu YA, Tukur Z, Irving H, Wondji CS. High frequency of $k d r$ L1014F is associated with pyrethroid resistance in Anopheles coluzzii in Sudan savannah of northern Nigeria. BMC Infect Dis. 2014;14:441.

56. Verhaeghen K, Van Bortel W, Roelants P, Backeljau T, Coosemans M. Detection of the East and West African kdr mutation in Anopheles gambiae and Anopheles arabiensis from Uganda using a new assay based on FRET/ Melt Curve analysis. Malar J. 2006;5:16.

57. Yewhalaw D, Van Bortel W, Denis L, Coosemans M, Duchateau L, Speybroeck N. First evidence of high knockdown resistance frequency in Anopheles arabiensis (Diptera: Culicidae) from Ethiopia. Am J Trop Med Hyg. 2010;83(1):122-5.

58. Nardini L, Christian RN, Coetzer N, Ranson H, Coetzee M, Koekemoer LL. Detoxification enzymes associated with insecticide resistance in laboratory strains of Anopheles arabiensis of different geographic origin. Parasit Vectors. 2012:5:113.

59. Kabula B, Kisinza W, Tungu P, Ndege C, Batengana B, Kollo D, et al. Co-occurrence and distribution of east (L1014S) and west (L1014F) African knock-down resistance in Anopheles gambiae sensu lato population of Tanzania. Trop Med Int Health. 2014;19(3):331-41.

60. WHO. Techniques to detect insecticide resistance mechanisms (Field and laboratory manual). 1998.

61. Cuamba N, Morgan JC, Irving H, Steven A, Wondji CS. High level of pyrethroid resistance in an Anopheles funestus population of the Chokwe district in Mozambique. PLoS One. 2010;5:6.

62. Morgan JC, Irving H, Okedi LM, Steven A, Wondji CS. Pyrethroid resistance in an Anopheles funestus population from Uganda. PLoS One. 2010;5:7.

63. Hargreaves K, Koekemoer L, Brooke B, Hunt R, Mthembu J, Coetzee M. Anopheles funestus resistant to pyrethroid insecticides in South Africa. Med Vet Entomol. 2000;14:181-9.

64. Githeko AK, Service MW, Mbogo CM, Atieli FK, Juma FO. Origin of blood meals in indoor and outdoor resting malaria vectors in western Kenya. Acta Trop. 1994;58:307-16.

65. Mbogo CM, Mwangangi J, Nzovu J, Gu W, Yan G, Gunter JT, et al. Spatial and temporal heterogeneity of Anopheles mosquitoes and Plasmodium falciparum transmission along the Kenyan coast. Am J Trop Med Hyg. 2003; 68(6):734-42.

66. Muturi EJ, Muriu S, Shililu J, Mwangangi J, Jacob BG, Mbogo C, et al. Effect of rice cultivation on malaria transmission in Central Kenya. Am J Trop Med Hyg. 2008;78(2):270-5.

67. Kamau L, Agai D, Matoke D, Wachira L, Gikandi G, Vulule JM. Status of insecticide susceptibility in Anopheles gambiae sensu lato and Anopheles funestus mosquitoes from western Kenya. J Insect Sci. 2007;8:11.

68. Bonizzoni M, Afrane Y, Dunn WA, Atieli FK, Zhou G, Zhong D, et al. Comparative transcriptome analyses of deltamethrin-resistant and -susceptible Anopheles gambiae mosquitoes from Kenya by RNA-Seq. PLoS One. 2012;7:9

69. Vulule JM, Beach RF, Atieli FK, Mount DL, Roberts JM, Mwangi R. Long-term use of permethrin-impregnated nets does not increase Anopheles gambiae permethrin tolerance. Med Vet Entomol. 1996;10:71-9.

70. Mbogo C, Baya N, Ofulla A, Githure J, Snow R. The impact of permethrin-impregnated bednets on malaria vectors of the Kenyan coast. Med Vet Entomol. 1996;10:251-9. 